\title{
Cirurgia parendodôntica com obturação simultânea dos canais radiculares: relato de caso clínico
}

\author{
KarisBarbosa Guimarães ${ }^{1}$ \\ Letícia Kirst Post ${ }^{1}$ \\ M arcelo Ferraro Bezerra ${ }^{1}$ \\ Cristina Pereira Isolan ${ }^{2}$ \\ Elaini Sickert H osni ${ }^{3}$
}

\section{Resumo}

A obturação do canal radicular simultânea ao ato cirúrgico está indicada nos casos em que o tratamento endodôntico convencional fracassou, não havendo regressão da lesão periapical, ou quando não é possível a obturação dos canais radiculares devido à presença de exsudação persistente. 0 presentecaso clínico visa a relatar a técnica deobturação do canal radicular simultânea ao ato cirúrgico, bem como enfatizar os passosoperatóriosa serem seguidos para obtenção do sucesso operatório.

Palavras-chave: apicectomia; obturação radicular; cirurgia perirradicular.

\section{INT RODUÇÃO}

A evolução técnica, científica e biológica nos tratamentos de canais radiculares vem proporcionando aumento nos índices de sucesso, atingindo índices variantes de 25 a 90\%. ${ }^{1}$

Entretanto, apesar de toda essa evolução, os tratamentos de canais radiculares são realizados, basicamente, através de passos operatórios técnicos que são sujeitos a falhas, acidentes e variados tipos de complicações em sua evolução clínica. ${ }^{2}$

Diante do fracasso do tratamento de canal radicular, existe a possibilidade de seu retratamento, mas nem sempre essa conduta é viável. ${ }^{2}$ A cirurgia parendodôntica mostra-se uma excelente alternativa para a resolução de problemas não solucionados pelos tratamentos convencionais e (ou) retratamento de canais radiculares. ${ }^{3}$ A presença de infecção no canal radicular é definida como razão primária de uma inflamação periapical ${ }^{4,5}$, e 0 procedimento cirúrgico não deverá ser considerado como de primeira escolha, pois não promove 0 desbridamento do canal radicular. ${ }^{6}$

A cirurgia parendodôntica está indicada em casos de persistência de inflamação periapical crônica, com extensas áreas radiolúcidas apicais, acessos coronais até o ápice radicular restritos, devido a um insuficiente selamento retrógrado ou pinos radiculares impossibilitados de remoção, perfuração e fratura do terço apical

\footnotetext{
1 M estranda. Programa de Pós-Graduação em Cirurgia e Traumatologia Buço-maxilo-facial. Faculdade de O dontologia. Pontifícia Universidade Católica do Rio Grande do Sul - PUCRS. Porto Alegre - RS

2 M estranda. Programa de Pós-Graduação em Reabilitação O ral. Universidade Veiga de Almeida. Rio de Janeiro - RJ

3 Professora de Cirurgia e Traumatologia Bucomaxilofacial. Universidade Federal de Pelotas. D outoranda. Programa de Pós-graduação em Estomatologia. Faculdade de 0 dontologia. Pontifícia Universidade Católica do Rio Grande do Sul - PUCRS. Porto Alegre - RS
}

Correspondência para / Correspondence to:

Karis Barbosa Guimarães

Av. Ipiranga, no. 6681/ bloco 06/ sala 209 - Partenon

90.619-900. Porto Alegre - RS - Brasil

Tel./fax: (55) 3320-3538

E-mail: karisguimaraes@yahoo.com.br ; letipel@terra.com.br 
radicular, além de calcificações pulpares no terço radicular.?

Alguns fatores podem interferir no prognóstico da cirurgia periapical, tais como as condições sistêmicas do paciente, o elemento dental envolvido (a classificação dentária, o número de dentes e localização), a quantidade e a localização de reabsorção óssea, a qualidade pré via do tratamento do canal radicular e (ou) retratamento, as restaurações e o grau de microinfiltração oclusal, os materiais cirúrgicos retrobturadores, a técnica envolvida, bem como a habilidade e experiência do cirurgião. ${ }^{1,8,} 9,10$

As modalidades cirúrgicas mais utilizadas para a resolução de dificuldades, acidentes e complicações na Endodontia podem variar desde uma simples curetagem com alisamento ou plastia apical, apicectomia, apicectomia com obturação retrógrada, até a obturação do canal radicular simultânea ao ato cirúrgico. ${ }^{2}$

A obturação do canal radicular simultânea ao ato cirúrgico compreende a obturação tridimensional do canal radicular concomitante à exposição cirúrgica do ápice dental. Essa modalidade cirúrgica representa um importante recurso a ser empregado dentro da cirurgia parendodôntica, desde que bem indicada. ${ }^{11}$

A obturação do canal radicular simultânea ao ato cirúrgico vem resolver aqueles casos rebeldes de extensas lesões periapicais crônicas, em que, além de estar o canal radicular bem instrumentado, já foram feitas várias trocas de curativo de pasta de hidróxido de cálcio, terapia antibiótica sistêmica e, mesmo assim, há a presença de exsudato inflamatório persistente, impedindo a conclusão do caso. ${ }^{2}$

Apresenta como contra-indicações a impossibilidade de desbridamento prévio, inflamação aguda presente e inacessibilidade ao ápice radicular. ${ }^{2,11}$

Assim, o objetivo deste trabal ho é relatar um caso clínico de obturação do canal radicular simultânea ao ato cirúrgico, enfatizando a técnica e os passos operatórios a serem seguidos para obtenção do sucesso operatório.

\section{CASO CLÍNICO}

Paciente do gênero masculino, 21 anos e da raça negra, procurou a Clínica de
Traumatologia do D epartamento de 0 dontologia Restauradora da U niversidade Federal de Pelotas, relatando um abaulamento na região de palato compreendida entre a linha média até 0 canino superior direito, com sintomatologia dolorosa e sensação de pressão na região. (FIGURA 1).

0 paciente, na avaliação anamnésica, apresentava história pregressa de traumatismo dento-alveolar, com luxação extrusiva dos dentes 11 e 12, há dois anos. N aquele momento, observou-se a presença de mobilidade temporária e ausência de alteração na coloração dentária.

Ao exame clinico, evidenciou-se dor à palpação, e, radiograficamente, foi evidenciada uma área radiolúcida que envolvia os ápices radiculares dos dentes 11 e 12, além de reabsorção externa na região cervical subgengival do incisivo central direito. (FIGURA 2; FIGU RA 3)

D urante a pulsão, obteve-se um líquido citrino com material purulento em pouca quantidade. 0 tratamento inicial envolveu anestesia, abertura coronária e neutralização do canal radicular pela técnica convencional e clássica², irrigando-o com hipoclorito de sódio a 1\% (Solução de M ilton). N essa primeira sessão, após a odontometria e terminado o preparo biomecânico, foi realizada a secagem do canal radicular e inserida a pasta de hidróxido de cálcio (Calen/ PM CC) como curativo de demora. 0 selamento coronário provisório foi realizado com óxido de zinco e eugenol. A medicação intra-canal foi trocada após duas, quatro e seis semanas. $0 \mathrm{~b}$ servada a instalação de exsudação persistente associada à lesão, optou-se realizar, concomitantemente, a terapia antibiótica sistêmica, a drenagem do material purulento, a qual não foi eficiente, pela consistência do material exsudado.

Dessa forma, modificou-se o plano de tratamento, optando-se pela intervenção cirúrgica com realização da obturação do canal radicular simultânea ao ato cirúrgico e curetagem do material cístico.

Foi realizada anestesia, por bloqueio da região a ser abordada, com complementação da anestesia infiltrativa. A incisão realizadafoi intrasulcular, utilizando-se uma lâmina de bisturi 


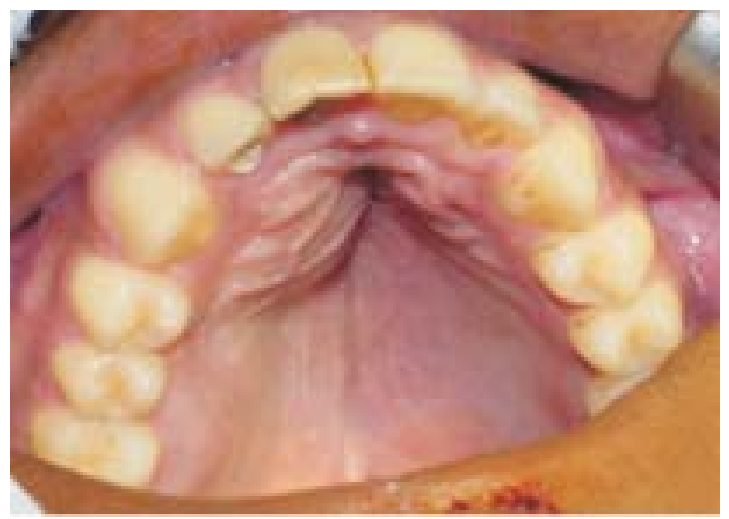

Figura 1 - Aspecto Clínico Inicial: Abaulamento naregião de palato compreendida entre a linha média atéo canino superior direito.

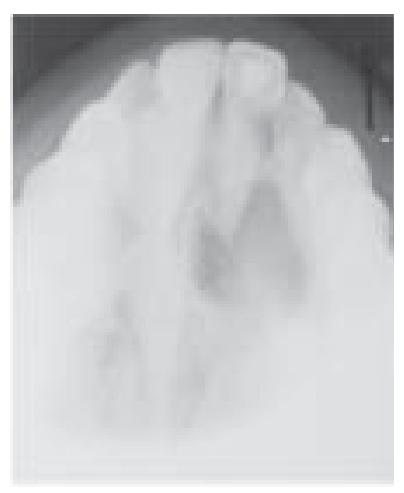

Figura2 - Radiografia inicial do dente 11, evidenciando a presença da lesão periapical.

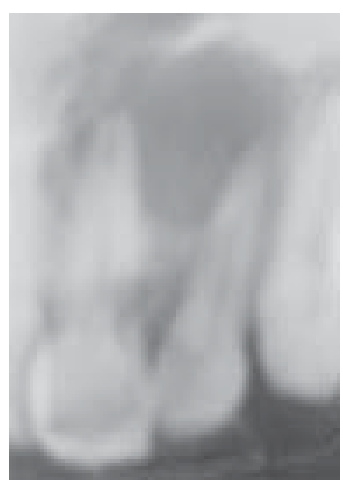

Figura 3 - Radiografiainicial do dente 12 , evidenciando a presença da lesão periapical.

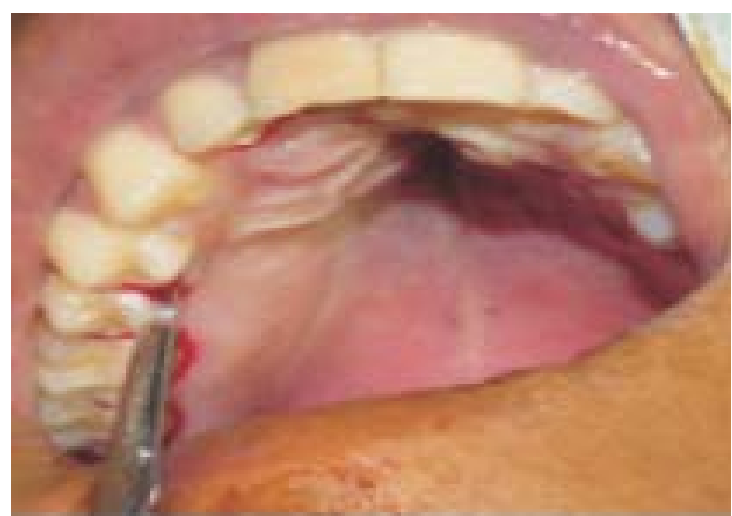

Figura 4 - Retalho mucoperiósteo composto de umaincisão intra-sul cular na palatina região compreendida entreos dentes segundo prémolar superior direito atécanino superior esquerdo.

número 15, estendendo-se do canino superior esquerdo até 0 segundo prémolar superior direito. (FIGURA 4)

O ptou-se pela incisão palatina pelo fato de ter sido constatado, previamente ao ato cirúrgico, áreas com reabsorção óssea palatina e abaulamento da parede palatina, com zonas de flutuação, além da preservação da tábua óssea vestibular. 0 deslocamento do retalho mucoperiostal foi realizado, observando-se a presença de uma loja óssea, a qual evidenciava um componente capsular cístico, de consistência firme e exsudato espesso, o que justificava a dificuldade para drenagem. (FIGURA 5)

Ao ser exposta toda a cavidade cirúrgica, e após irrigação abundante com clorexidrina a $0,12 \%$, foi realizada a curetagem e remoção total da cápsula cística da lesão. (FIGURA 6; FIGURA 7)

Com o auxílio de broca tronco-cônica número 700, em alta-rotação e sob abundante irrigação com soro fisiológico, foi realizada a apicectomia, no sentido disto-mesial ligeiramente inclinada para vestibular, formando um ângulo de 450 com o longo eixo dental. D essa forma, seccionou-se a porção apical do elemento dentário 11. (FIGURA 8).

Concluído o corte apical, iniciou-se 0 preparo do canal radicular exposto, com remoção do selamento coronário provisório e remoção da pasta de hidróxido de cálcio, utilizando- 
se irrigação abundante com clorexidrina $0,2 \%$ e, posteriormente, soro fisiológico. Foram utilizadas limas Kerr, número 10 até 40 , com ligeiro transpasse, para se conseguir o esvaziamento completo do canal radicular. A secagem foi realizada com ponta de papel absorvente e se guiu-se a obturação do canal radicular. 0 cone principal foi envolto em cimento obturador e tracionado através do forame, para se obter um bom travamento apical. Realizou-se condensação lateral e colocação de cones acessórios para total preenchimento do canal radicular.

A pós certificação do vedamento radicular, foi realizado o corte dos excessos dos cones de guta-percha da porção coronária, condensação vertical e sel amento provisório da câmara pulpar. Em seguida, realizou-se o corte dos excessos apicais com lâmina de bisturi número $15 \mathrm{e}$ alisamento apical com ponta diamantada de granulação ultrafina. Quanto à área de reabsorção externa na região cervical do incisivo central direito, durante 0 trans-cirúrgico, adicionou-se MTA (Trióxido M ineral Agregado) na região, esperando-se estagnamento da reabsorção.

Após preenchimento da loja cirúrgica com coágulo, o retalho cirúrgico foi reposicionado e a sutura realizada, com pontos interrompidos. (FIGURA 9).

Foi realizada a prescrição de antiinflamatório por três dias e de antibiótico por sete dias. A sutura foi removida após 5 dias. As radiografias foram obtidas logo após 0 ato cirúrgico e após seis meses. (FIGURA 10)

0 resultado do exame anátomo-patológico, veio a confirmar o diagnóstico clínico e radiográfico de cisto inflamatório.

\section{ISC U SSÃO}

Índices de sucessos e insucessos nas cirurgias parendodônticas são bastante extensos. ${ }^{12}$ Lesões periodontais apicais são decorrentes da contaminação bacteriana ao longo do canal radicular. A cirurgia parendodôntica objetiva promover 0 isolamento do canal radicular, e conseqüentemente, a contaminação bacteriana dos tecidos apicais e periapicais, estimulando, dessa forma, a cicatrização. ${ }^{13} \mathrm{M}$ as ressalta-se que o procedimento cirúrgico só deve ser instituído após o tratamento convencional do conduto radicular, ou quando os índices de risco e benefício do tratamento convencional resultarem em um prognóstico incerto de sucesso. ${ }^{6} 0$ presente caso está de acordo com recomendação de Friedman ${ }^{13} \mathrm{e}$ de M oseiwitsch, Trope e H ill6, sobre a instituição da cirurgia parendodôntica somente após findada a tentativa de tratamento por meio da endodontia convencional.

A obturação do canal radicular simultânea ao ato cirúrgico deve ser realizada quando não se consegue conter a exsudação persistente por meio de medicação intracanal e medicação sistêmica. ${ }^{2}, 14$

Estudos têm demonstrado que uma correta instrumentação do canal, acompanhada de irrigação abundante, é capaz de reduzir drasticamente o número de bactérias 5 . Entretanto, 0 uso de medicação de demora com ação bactericida tem sido recomendado para se obter uma melhor desinfecção do canal radicular. ${ }^{14}$

Segundo Tronstad, 15, o uso de hidróxido de cálcio como curativo de demora no interior do canal radicular tende a modificar o $\mathrm{pH}$ da superfície da raiz de ácido, pela lesão existente, para básico, através da difusão pelos túbulos dentinários. Assim, o hidróxido de cálcio tem como principal função debelar a infecção e proporcionar um meio básico para a neo-formação óssea. $N$ os casos em que isso não ocorre e existe a persistência da exsudação no canal radicular, impedindo a obturação, o hidróxido de cálcio também deve ser utilizado, para que se obtenha a desinfecçãa dos canais radiculares, proporcionando um resultado satisfatório após a cirurgia parendodôntica complementar. ${ }^{16}$

No caso relatado, houve dificuldade em debelar a infecção, pois a área comprometida era extensa e, mesmo utilizando-se medicação intracanal e sistêmica, não houve o resultado esperado. Sendo assim, optou-se pela realização da obturação do canal radicular simultânea ao ato cirúrgico.

$\mathrm{N}$ a literatura, foram encontrados trabaIhos concordantes com o presente artigo na escolha da técnica de obturação radicular simul- 


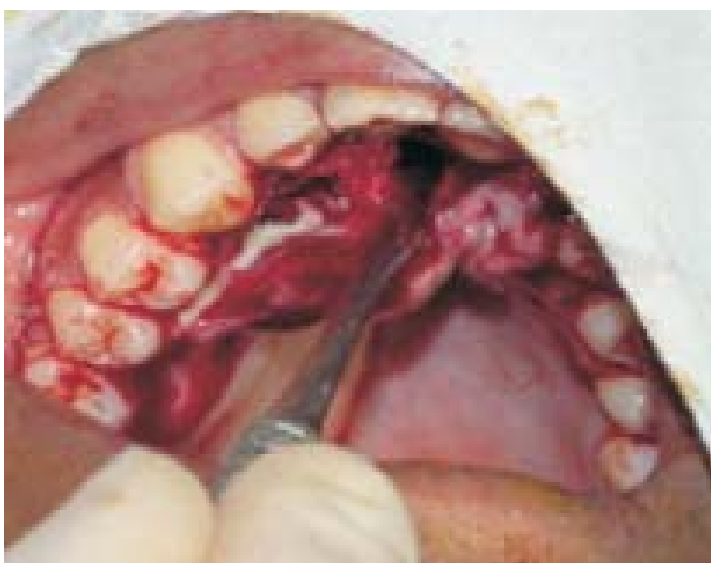

Figura 5 - D eslocamento do retal ho mucoperiósteo e constatação de processo infeccioso.

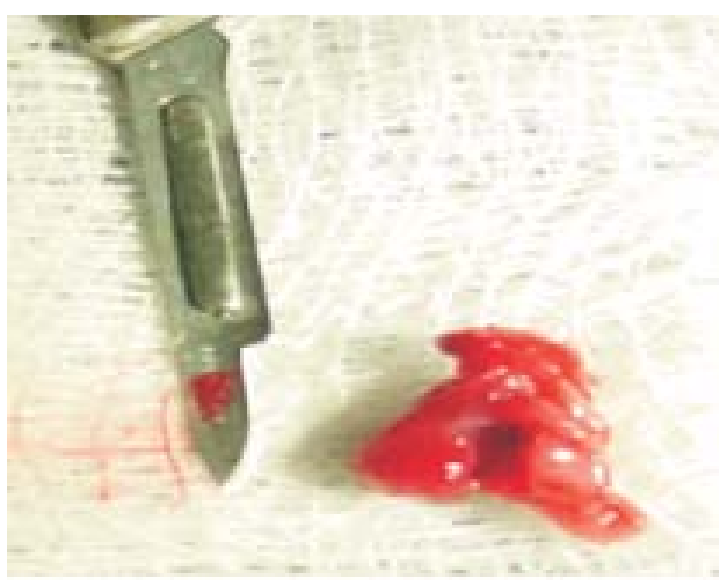

Figura 6 - Lesão capsular cística íntegra, enucleada pós curetagem periapical..

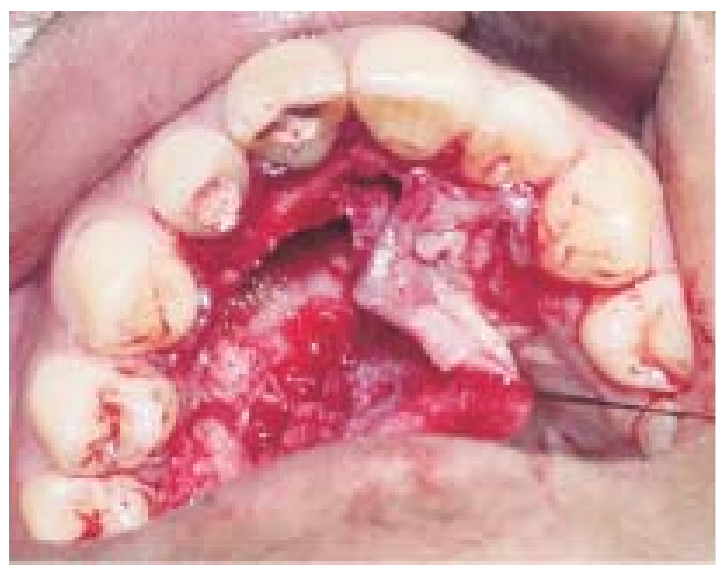

Figura 7- Aspecto da loja cirúrgica, pós enucleação do conteúdo cístico.

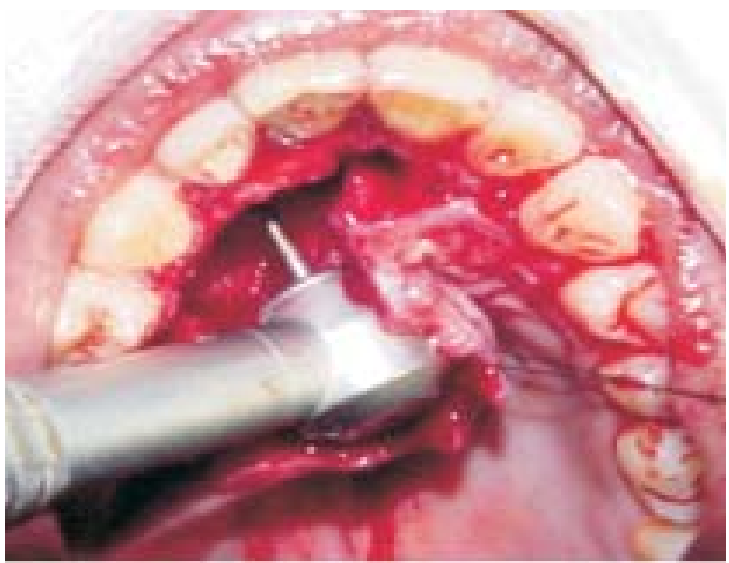

Figura 8- Apicectomia do ápice radicular do elemento 11 com ligera inclinação paravestibular.

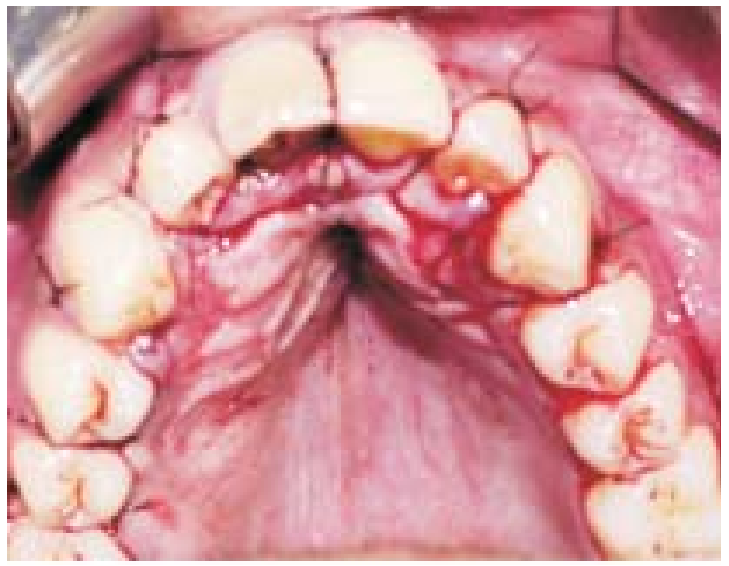

Figura 9 -Aspecto final após a sutura.

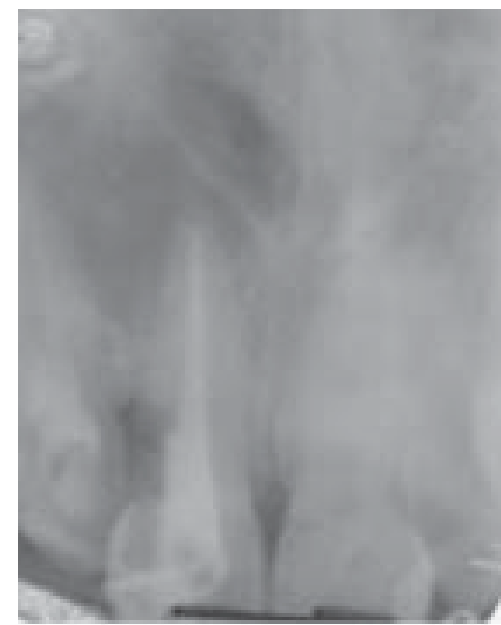

Figura 10- Pós 0 peratório após 06 meses, evidenciando neoformação óssean naloja cirúrgica. 
tânea ao ato cirúrgico que também obtiveram sucesso na realização de tal procedimento.11, 12, 14

A exposição cirúrgica do ápice facilita a biomecânica do canal radicular, permite uma obturação mais eficiente, com condensação vigorosa sem a preocupação de extravasamento de material obturador. Removendo-se 0 mate rial patológico do periápice, obtém-se um conduto ausente de exsudação, permitindo a completa obturação e regeneração do tecido de sustentação. 0 acesso cirúrgico ao ápice permite a eliminação de elementos estranhos na região, como material obturador extravasado ou instrumento fraturado, ou ainda a remoção do ápice radicular fraturado., ${ }^{211}$

0 acompanhamento radiográfico pósoperatório apresenta cicatrização incerta após um ano, enquanto que a completa cicatrização é alcançada em quatro anos. Elementos dentais com sinais de sucesso ou insucesso evidenciamse nos primeiros seis a doze meses de acompanhamento pós-operatório. ${ }^{12}$
A associação entre o tempo decorrido e o diâmetro da cavidade óssea formada pela lesão é determinante nas evidências radiográficas do processo cicatricial. 0 presente caso concorda com Jansson e colaboradores 17, pois observou-se a diminuição progressiva da cavidade e neoformação óssea em apenas seis meses de acompanhamento pós-operatório.

\section{CONSIDERAÇÕES FINAIS}

Conclui-se, que as técnicas cirúrgicas parendodônticas de obturação do canal radicular simultânea ao ato cirúrgico promovem um bom vedamento radicular e, quando associadas à remoção de todo tecido infectado do periápice e do 0sso, permitem o estabelecimento de condições favoráveis para neoformação óssea.

\title{
Endodontic surgery with simultaneousrootsfilling: report of dinical case
}

\begin{abstract}
The endodontic surgery with simultaneous root filling is indicated when the conventional endodontic treatment fails and there was no regression of periapical lesion, or when the root canal obturation is impossible because of the presence of the persistent exudation. The present clinical case aims to report the endodontic surgery with simultaneous root canal obturation as well as to emphasize the operative steps to be followed for obtaining of the operative success
\end{abstract}

Keywords: Apicoectomy; Root canal obturation; O ral surgery.

\section{REFERÊNCIAS}

1 GUTMANN, J.L.; HARRISON, J.W. Surgical endodontics. Boston: Blackwell, 1991.

2 LEONARDO, M.R.; LEAL, J.M. Endodontia: tratamento de canais radiculares. 3.ed. São Paulo:Panamericana, 1998.

3 LEWIS, R. D.; BLOCK, R.M. M anagement of endodontic failures. 0 ral Surg. 0 ral Med.
O ral Pathol., St. Louis, v.66, n.6, p.711-721, 1988.

4 SJ ÖGREN, U. et al. Influence of infection at the time of root filling on the outcome of endodontic treatment of teeth with apical periodontitis. Int. Endod. J., London, v.30, p.297-306, 1997. 
5 SUNDQVIST, G. et al. M icrobiologic analysis of teeth with failed endodontic treatment and the outcome of conservative retreatment. 0 ral Surg. 0 ral Med. 0 ral Pathol. O ral Radiol. Endod., St. Louis, v.85, p.86-93, 1998.

6 MOISEIWITSCH, J.R.D.; TROPE, M.; HILL, C. N onsurgical root canal therapy treatment with apparent indications for rootend surgery. 0 ral Surg. 0 ral M ed. 0 ral Pathol. O ral Radiol. Endod., St. Louis, v.86, p.335340, 1998.

7 WESSELINK, P.R. et al. Radiografic evaluation of cases referred for surgical endodontic. Int. Endod. J., London, v.35, p.472-477, 2002.

8 ALLEN, R.K.; NEWTON, C.W.; BROW N JÚ NIO R, C.E. A statistical analysis of surgical and nonsurgical endodontic retreatment cases. J. Endod., Baltimore, v.15, p.261-266, 1989.

9 AUGUST, D.S. Long-term, post surgical results on teeth with periapical radiolucencies. J. Endod., Baltimore, v.22, p.380-388, 1996.

10 LUSTM SN N, J.; FRIEDMAN, S.; SH AH ARABANY, V. Relation of pre and intra operative factors to prognosis of posterior apical surgery. J. Endod., Baltimore, v.17, p.239-241, 1991.

11 KU GA, C.M . et al. Cirurgia parendodôntica com obturação simultânea dos canais radiculares.
R. Assoc. Paul. Cir. D ent., São Paulo, v.46, n.4, p.817-820, 1992.

12 RUD , J.; ANDREASEN, J.0.; JEN SEN, J.E. Radiographic criteria for the assessment of healing after endodontic surgery. Int. J. O ral Surg., Copenhagen, v.1, n.4, p.195-214, 1972.

13 FRIEDM AN, S. Retrograde approaches in endodontic therapy. Endod. D ent. Traumatol., Copenhagen, v.7, p.97-107, 1991.

14 ARAÚJO, E.A.F. de et al. O bturação do canal radicular simultânea ao ato cirúrgico: caso clínico. JBC: J. Bras. Clin. $\mathbf{O}$ dontol. Int., Curitiba, v.8, n.46, p.319-323, 2004.

15 TRO N STAD, L. Root resorption, etiology, terminology, and clinical manifestation. Endod. Dent. Traumatol., Copenhagen, v.4, p.241252, 1988.

16 D AN IN, J. et al. O utcomes of periradicular surgery in cases with apical pathosis and ntreated canals. 0 ral Surg. 0 ral M ed. 0 ral Pathol. 0 ral Radiol. Endod., St. Louis, v.87, p.227-232, 1999.

17 JAN SSO N, L. et al. Relationship between apical and marginal healing in periradicular surgery. 0 ral Surg. 0 ral Med. 0 ral Pathol. 0 ral Radiol. Endod., St. Louis, v.83, p.596601, 1997. 